\title{
Gramática da Matemática e seus usos
}

\author{
Grammar of Mathematics and its uses
}

\author{
Marisa Rosâni Abreu da Silveira
}

\begin{abstract}
Resumo: Este artigo tem o objetivo de analisar o uso da gramática da Matemática em situações de ensino e de aprendizagem. Tal análise é feita com base na filosofia da linguagem, segundo Wittgenstein e por alguns de seus comentadores. Para tanto, nesse texto teórico, discutimos a universalidade da linguagem matemática; a necessidade da tradução da linguagem matemática para a linguagem natural; e o uso da gramática da Matemática e alguns de seus desdobramentos. A gramática da Matemática é o conjunto de regras que determinam o uso correto de símbolos e palavras do vocabulário matemático e é na aplicação dessas regras que o aprendiz compreende o sentido dos conceitos matemáticos.
\end{abstract}

Palavras-chave: Linguagem. Matemática. Universalidade. Gramática. Wittgenstein.

Abstract: This paper aims to analyze the use of Mathematics grammar in teaching and learning situations. Such analysis is made on the basis of Wittgenstein's second language philosophy and some of his commentators. To do so, our theoretical text, we discuss the universality of mathematical language; the need to translate mathematical language into natural language; and the use of mathematical grammar and some of its developments. The

Marisa Rosâni Abreu da Silveira Doutorado em Educação. Professora do Programa de Pós-Graduação em Educação em Ciências e Matemáticas da Universidade Federal do Pará (UFPA). Pará, Brasil.

iD orcid.org/0000-0002-3147-9478

$\bowtie$ marisabreu@ufpa.br

Recebido em 30/03/2020

Aceito em 12/05/2020

Publicado em 15/06/2020 mathematical grammar is the set of rules that determine the correct use of symbols and words of the mathematical vocabulary and it is in the application of these rules that the apprentice understands the meaning of the mathematical concepts.

Keywords: Language. Mathematics. Universality. Grammar. Wittgenstein.

\section{Introdução}

A questão epistemológica que envolve o conhecimento matemático é debatida por diversas vertentes educacionais com seus respectivos referenciais teóricos; a questão como 0 sujeito aprende? pode ser respondida por diferentes eixos teóricos. Atualmente podemos destacar duas formas de pensar a produção deste conhecimento, uma delas amparada na filosofia da consciência em que se enquadra pesquisas pelos processos mentais do sujeito aprendente, e outra que busca respostas às questões epistemológicas via filosofia da linguagem. A maioria destas vertentes está apoiada em pesquisas relativas aos processos cognitivos, tais como aquelas que se filiam ao construtivismo piagetiano. Neste artigo, nos preocupamos com a busca de respostas para a questão de como podemos ensinar Matemática dando ênfase aos processos linguísticos do sujeito aprendiz. 
Para respondermos tal questão, nos debruçamos na filosofia da linguagem segundo Ludwig Wittgenstein, filosofia que tem como principal obra as Investigações Filosóficas. Tal filosofia que difere daquela do Tractatus Logico-Philosophicus, sua primeira obra que contempla a lógica da linguagem. A segunda filosofia retoma questões levantadas na primeira, no sentido de buscar outro sentido aos problemas filosóficos, tais como os estudos da linguagem, sentidos encontrados nos jogos de linguagem - importante conceito que faz analogia entre jogo e linguagem e subtende uma forma de vida.

Para Wittgenstein (1987), a Matemática faz parte do aparelho da linguagem e sua aplicação faz dela uma linguagem propriamente dita. Nesse sentido, a Aritmética é a gramática dos números. A gramática é o conjunto de regras que governam a Aritmética. Estas regras não podem ser modificadas porque elas nasceram do acordo entre homens e posteriormente passaram a ser consideradas normas. Um cálculo aritmético deve obter o resultado que já está previsto pela Gramática; $2+3$ deve ser igual a 5 porque existe uma regularidade na forma de fazer este cálculo.

Ludwig Wittgenstein se preocupa com a linguagem e com as regras de sua Gramática. Assim, o filósofo austríaco não quis tratar de processos mentais, ele diz saber da existência de tais processos, mas não quis se preocupar com eles. Sabedores desta filosofia, alguns educadores se engajaram na sua filosofia para tratar dos problemas da Educação Matemática via processos linguísticos.

Neste artigo pretendemos também refletir a questão de como o aprendiz lida com conceitos matemáticos em meio a jogos de linguagem. Tal questão é vislumbrada perante a universalidade da Matemática e sua linguagem, como também o uso da gramática da Matemática em situações de ensino e de aprendizagem. Ao analisarmos a relação da Matemática e a linguagem nessas atividades, buscamos trazer à tona outros importantes conceitos da filosofia de Wittgenstein, assim como procuramos ilustrar com pesquisas educacionais que corroborem com as questões aqui levantadas.

A Matemática é humana porque também é histórica. A Matemática, dependendo da cultura, pode ter práticas diferentes, usos diferentes. Os conceitos matemáticos possuem uma estrutura independente de suas determinações culturais, mas essas determinações culturais não são independentes da estrutura matemática. A objetividade da Matemática nos leva a pensar que mesmo povos distantes geograficamente possuem a capacidade de construir conceitos 
matemáticos semelhantes, tais como o conceito de derivada de uma função, em que foi construído concomitantemente por Gottfried Wilhelm Leibniz na Alemanha e por Isaac Newton na Inglaterra.

Para atingirmos nosso objetivo, em primeiro lugar destacamos alguns pontos que nos remete à universalidade da linguagem matemática; em segundo lugar analisamos a necessidade da tradução da linguagem matemática para a linguagem natural; em terceiro lugar, o uso da gramática da Matemática e alguns de seus desdobramentos; em quarto lugar discutimos três pesquisas que envolvem aplicação de regras matemáticas em situações de ensino e de aprendizagem, tendo como principal eixo de análise a filosofia da linguagem de Wittgenstein. Por último, tecemos nossas considerações tentando levantar os principais pontos discutidos nesse artigo.

\title{
2 Universalidade da linguagem matemática
}

\begin{abstract}
A insistência sobre os aspectos antropológicos e culturais andam de mãos dadas com a explicação inter-teórica da matemática e com a história de seus procedimentos, mostra como este saber-fazer que se estende sobre milênios é construído sobre 0 esforço dos seres humanos e nada além disso: a matemática não se origina em uma realidade perceptível em si, e a estrutura neuro-biológica (cérebro) não faz o suficiente para dar conta da produção de conceitos matemáticos pelo ser humano. (MLIKA, 2007)
\end{abstract}

Para Caveing (2004), a universalidade da Matemática é uma universalidade da linguagem e de práticas desenvolvidas com saberes matemáticos. A Matemática é uma atividade de passagem de um conceito a outro formando uma rede conceitual, em que um conceito depende de outro. A necessidade inter-teórica de formação de conceitos que estrutura a Matemática, que encontramos em todas as culturas, testemunha sua objetividade como tal, e sua independência do mundo empírico concorda com a possibilidade de variantes. O conceito de número inteiro é independente de sistemas de numeração, mas os sistemas numéricos não são independentes dele, isso explica como todos os sistemas têm alguns traços em comum. Todos estes sistemas são conforme o conceito de número, mesmo que os seus usuários não o saibam. Essa é a universalidade e necessidade de idealidades matemáticas que explicam por que etnomatemáticas podem ser diferentes.

A Matemática não tem origem fora dela, não tem origem no mundo empírico. Dois mais três são cinco não porque duas maçãs mais três maçãs são cinco maçãs, e sim, porque dois mais três são cinco é uma norma. Se há influências entre as culturas é na prática matemática e nas 
propriedades de objetos e conceitos matemáticos que é preciso procurar a origem da Matemática, pois ela pode ter práticas diferentes. Para Mlika (2015), sua universalidade significa uma forma de intelectualidade, tal que a Matemática cruza as culturas em tal e tal momento de sua história empírica e deixa aparecer no contato com a variedade de contextos e exigências culturais algumas de suas características essenciais em detrimento de outras. $O$ universalismo cultural que favorece a objetividade das matemáticas supõe que sejam pensamentos que agregam as diferenças e a universalidade. Na determinação destes, podemos reconhecê-los no mesmo movimento.

O ponto de vista de Caveing (2004) reconhece que a Matemática não é nem do céu, nem da terra. Os sistemas numéricos não têm a mesma produtividade matemática, mas o que todos eles têm em comum é o fato de que produzem usos da Matemática com resultados compatíveis. No entanto, a linguagem, a escrita, a organização da vida em grupo, as tradições locais, a relação ao outro e ao mundo, a existência de uma hierarquização de funções sociais etc., tudo isso intervém nos aspectos culturais da Matemática. Mas mesmo se forem diferentes, estes sistemas expressam as possibilidades de idealidades elas mesmas e com base em muitos pontos. Essa objetividade não é fundada na empiria nem em objetos de qualquer tipo, mas nas condições a priori da relação de um sujeito concreto no mundo. Matemática é o fruto de um trabalho humano que se opera por desvios no pensamento, na linguagem e na prática.

Wittgenstein reconhece a autonomia da Matemática perante às manifestações empíricas, quando afirma que criamos o conjunto dos números inteiros não pelo fato que temos dívidas, e sim porque havíamos criado o conjunto dos números naturais. Assim, por uma necessidade interteórica vamos criando os conjuntos numéricos conforme nossas necessidades e descobertas.

\footnotetext{
Assim, pois, você diz que o acordo entre os homens decide o que é correto e o que é falso? Correto e falso é o que os homens dizem; e na linguagem os homens estão de acordo. Não é um acordo sobre as opiniões, mas sobre o modo de vida (WITTGENSTEIN, 2009, p. 123).

Esta reflexão [a respeito da concordância entre os homens] deve valer também para a matemática. Se não houvesse essa total concordância, os homens não aprenderiam a matemática que aprendemos. Seria mais ou menos diferente da nossa, até o ponto de ser irreconhecível. (WITTGENSTEIN, 2009, p. 293)
}

Dessa forma, o automovimento ou movimento inter-teórico, da Matemática é concedido por Caveing e Wittgenstein. Como vimos, Leibniz e Newton habitavam em diferentes países e tiveram a necessidade de criar o conceito de derivada de uma função, cada um em uma disciplina diferente, o primeiro na Matemática e os segundo na Física. Isto é uma prova que a Matemática 
tem um campo próprio e necessário para o avanço de sua teoria.

\section{Tradução da linguagem matemática para a linguagem natural}

Os textos matemáticos podem ser escritos por meio da linguagem natural e/ou da linguagem matemática. A primeira é polissêmica e a segunda é codificada e pretende ter um sentido único. A linguagem matemática não possui oralidade e utiliza a linguagem natural para que o texto possa ser lido, ou seja, o texto escrito em linguagem matemática precisa ser traduzido para a linguagem natural, porém, ele possui um resíduo que fica subentendido no processo de codificação. Tal resíduo precisa ser interpretado para que o texto tenha sentido. 0 resíduo é aquilo que foi extinto pelo processo de formalização da linguagem natural, tal como afirmar que $x \in \mathbb{N} \mid x \geq 2$ subentende que $x=2,3,4, \ldots$

Os textos matemáticos são governados por regras matemáticas e estão envolvidos por uma rede de conceitos, ou seja, a Matemática é um jogo de signos segundo regras relacionadas com a formação de conceitos. Aplicar uma regra de decodificação é traduzir o texto que está codificado. Neste sentido, decodificar é descobrir uma determinação conceitual; é transformar o texto codificado em palavras com sentido, de certa forma é traduzir de uma língua para outra. Esta tradução é um jogo de linguagem que podemos encontrar usos equivalentes com palavras da linguagem natural, porém essas palavras podem ter mais de um sentido, já que nossa linguagem é polissêmica e muda conforme o contexto em que as palavras são empregadas.

Jogo de linguagem para Wittgenstein é a analogia entre jogo e linguagem, palavras com sentido que possuem uma forma de vida nas palavras pronunciadas. Os participantes do jogo se compreendem mutuamente, tal como quando um pedreiro ao dizer lajota, seu colega lhe entrega uma lajota, ou quando o professor diz um triângulo retângulo, seu aluno desenha um triângulo com um ângulo de noventa graus.

\footnotetext{
Apresentam-me uma sentença em um código desconhecido, juntamente com a chave para decifrá-lo. Então, em certo sentido, tudo o que é exigido para o entendimento da sentença me foi dado. $E$, contudo, se me perguntassem se entendi a sentença, eu deveria responder "Tenho de decodificá-la primeiro" e, apenas quando a tivesse decodificada diante de mim, como uma sentença em inglês, eu diria "agora a entendo". Se agora levantarmos a questão "Em que momento da tradução para o inglês começa o entendimento?", obteremos um vislumbre da natureza do que é chamado "entendimento" (WITTGENSTEIN, 2010, p. 30).
}

O entendimento é necessário para que haja aprendizagem. Uma proposição matemática 
apresentada em códigos matemáticos precisa ser decodificada, tal como quando nos deparamos com uma frase em língua estrangeira. Não basta apenas substituir os códigos por palavras, é necessário dar sentido ao texto conforme o contexto matemático de sua aplicação. A expressão $x \in \mathbb{N} \mid x \geq 2$ corresponde a diversas constatações subentendidas, a saber, $x$ pertence ao conjunto dos números naturais, $x$ é maior que dois incluindo 2 .

\begin{abstract}
Traduzir de uma língua para outra é uma tarefa matemática, e traduzir p. ex. um poema lírico para uma língua estrangeira é muito análogo a um problema matemático. Pois pode-se certamente colocar o problema "Como deve ser (p. ex.) traduzida" - i.e. substituída - "essa piada por uma piada na outra língua?"; e o problema pode também estar resolvido; mas um método, um sistema para sua resolução, não houve (WITTGENSTEIN, 1989, §698).
\end{abstract}

Traduzir de uma língua para outra é uma tarefa matemática porque como vimos é necessário traduzir o texto codificado para a linguagem natural para que 0 texto tenha sentido. Não existe um único método porque todo o jogo de linguagem depende do contexto em que as palavras estão sendo empregadas, bem como depende dos participantes do jogo.

O uso de seus signos constitui a Matemática como uma linguagem. Nesse sentido, "tratam as matemáticas acerca dos signos no papel? Esses signos são seus objetos tanto como as figuras de madeira são o objeto do xadrez" (WITTGENSTEIN, 2014, p. 496). A linguagem da Matemática não é a própria Matemática, pois se faz Matemática no uso dos signos. A Matemática é uma atividade humana.

Proposições matemáticas são regras gramaticais, tais como $2+2=4$. As proposições matemáticas apontam para uma necessidade objetiva, enquanto as proposições empíricas são atendidas por acordos entre os homens. Na proposição empírica, duas maçãs mais duas maçãs pode ser quatro maçãs mesmo que uma delas seja maior que outra. Já na proposição matemática, $2+2$ deve ser igual a 4 porque é uma proposição normativa. Nesse sentido, o ensino e a aprendizagem da Matemática constituem-se em jogos de linguagem entre professor e alunos quando buscam um mesmo universo discursivo com palavras que tenham sentido como uma forma de vida.

A gramática não diz como a linguagem tem que ser construída para cumprir com sua finalidade, para agir desta ou daquela maneira sobre as pessoas. Ela apenas descreve o emprego dos signos, mas de maneira alguma os elucida (WITTGENSTEIN, 2009, § 496).

A Gramática é a composição de regras que descreve o emprego, o uso dos signos de 
nossa linguagem, que tem a função de comunicação. No entendimento de Wittgenstein (1986), "a comunicação oral deixa na memória uma impressão muito mais frágil que a visualização da palavra" (p. 237). É por isso que precisamos escrever no quadro quando estamos ensinando. Dizemos o triângulo é um polígono de três lados e ao mesmo tempo desenhamos o triângulo no quadro. E aí reside também a importância do gesto ostensivo - gesto de apontar para o triângulo e ao mesmo tempo dizer este polígono é um triângulo - tal como discutido por Oliveira e Silveira (2016), em pesquisa que teve como objetivo tratar da utilização de gestos ostensivos como auxiliares do professor no processo de mostrar provas matemáticas aos seus alunos.

De acordo com Wittgenstein, a comunicação é mais eficaz por meio da expressão escrita que pode ser salientada por meio do gesto ostensivo, como também é mais fácil de memorizar. Neste sentido, o aluno cego, para alguns aspectos da Matemática, fica prejudicado e, aí sim, torna-se mais eficaz a comunicação oral.

A gramática de uma língua não é registrada e não passa a existir até que a língua já tenha sido falada por seres humanos por um longo tempo. Similarmente, os jogos primitivos são jogados sem que suas regras sejam codificadas e até mesmo sem a formulação de uma única regra (WITTGENSTEIN, 2010, p .44).

Quando uma criança aprende a falar, ela utiliza jogos primitivos - jogos em que a criança aprende as primeiras palavras de sua língua materna. Após aprender a falar, começa a compreender a Gramática e assim aprende o uso das palavras em diferentes contextos, da mesma forma que aprende na escola novas palavras, novos conceitos. Para essa aprendizagem é necessária a prática do uso das palavras que governam os conceitos. É no uso da palavra que aprendemos o seu significado, no uso de regras da Gramática que subentendem nossos conceitos. A objetividade da Matemática pressupõe um conjunto de conceitos que possui uma organização interna, tal como o conjunto dos números naturais que está contido no conjunto dos números inteiros e, por sua vez, o conjunto dos números inteiros está contido no conjunto dos números racionais e assim por diante. De certa forma, nós criamos a objetividade por meio da linguagem, objetividade que faz parte do automovimento da Matemática — movimento inter-teórico da Matemática.

\section{Os usos da gramática da Matemática}

A essência se expressa na gramática. (WITTGENSTEIN, 2009, p. 158). 
A Gramática conecta as regras que fornecem o significado da palavra ao seu uso, sua aplicação. Ela funciona como um meio de orientação do uso das palavras, regras de emprego das palavras. De acordo com Simões (2008, p. 149), se o filósofo entender a gramática das palavras e o uso de suas regras, "se ele conseguir livrar-se das analogias enganadoras" e "ter uma visão panorâmica dos problemas suscitados pelo mau uso da linguagem", como também "deixar de se alimentar de um só tipo de exemplo", ele pode perceber que os problemas filosóficos podem ser resolvidos pela compreensão da linguagem.

Os axiomas da Matemática são proposições da sintaxe, os enunciados matemáticos são regras de sintaxe, proposições gramaticais. Assim, por um ponto passam infinitas retas é uma proposição da gramática da Matemática que permite compreender que se queremos apenas uma reta devemos nos amparar em outro postulado, a saber, por dois pontos passa uma única reta; a proposição a soma dos ângulos de um triângulo é 180 graus é uma proposição da sintaxe (WITTGENSTEIN, 2003).

As proposições têm uma objetividade que não é a de um estado mental, são modeladas dentro da Gramática, com padrões e expectativas que tocam na linguagem, correlacionadas por uma relação interna. A questão de como sair da linguagem para alcançar o real está má colocada e mostra que a verdadeira chave está na língua, no que é gramatical, não passa através das paredes da linguagem (CHAUVIRÉ, 2008).

Aceitar como certa uma proposição significa usá-la como regra gramatical the tirando as incertezas (WITTGENSTEIN, 1983). O fato de que o aluno resolve uma equação do segundo grau, sem saber dizer o que este tipo de equação significa, segundo Wittgenstein (1983), é o fato de que podemos construir gramaticalmente de forma correta uma proposição matemática sem compreender seu significado. A gramática de nossa Aritmética mostra, por exemplo, que $25 \times 25$ igual a 625. A Matemática não precisa de fundamentos; as proposições matemáticas precisam de uma clarificação da sua gramática. No entender de Wittgenstein (2003), "a gramática descreve 0 uso de uma palavra em uma língua" (p. 42) e, nesse sentido, "a gramática da palavra 'conhecer' não é a gramática de um 'estado de consciência', mas algo diferente. E há apenas uma maneira de aprendê-lo: ver como a palavra é usada na prática". (p. 51).

Os processos mentais não são de interesse para os estudos da linguagem porque queremos saber aquilo que o aprendiz diz ou escreve sobre determinado conhecimento, ou seja, ver como este conhecimento é usado na prática do uso das palavras. 
Estamos inclinados a chamar entendimento um processo mental ou um estado de espírito. Isso o caracteriza como um processo hipotético etc., ou, antes, como um processo (ou estado) no sentido de uma hipótese. Isto é, banimos a palavra "entendimento" para uma região particular da gramática.

A gramática de um estado ou processo mental realmente é, em muitos aspectos, similar à de, por exemplo, um processo cerebral. A principal diferença talvez seja a de que, no caso de um processo cerebral, se admite que uma verificação direta é possível; o processo em questão talvez possa ser visto abrindo-se o crânio. Mas não há espaço para uma "percepção imediata" similar na gramática do processo mental. (Não há tal movimento nesse jogo.) (WITTGENSTEIN, 2003, p. 59).

Não temos acesso aquilo que o sujeito pensa. O pensamento é um tipo de linguagem que pode ser expresso por meio de palavras, mas não podemos afirmar que os atos mentais necessariamente acompanham nossas palavras. Wittgenstein (2010) afirma que para exprimirmos uma ideia, tentamos traduzir a linguagem mental em linguagem verbal de tal forma que se alguém nos sugere algumas palavras para a expressão desta ideia podemos rejeita-las até o momento em que umas palavras sugeridas contempla o olhar de nosso espírito e dizemos: "é exatamente isso que eu queria dizer!". Para Wittgenstein, o pensamento pode vir da leitura de uma frase escrita no papel, de uma imagem que nos vem à cabeça, do espírito que nos sugere uma música etc.

A relação entre o aprendizado do sentido de uma palavra e sua utilização tem relação com o conhecimento de regras gramaticais que expressam a maneira em que as palavras devem ser utilizadas. Assim, "é evidente que a gramática da palavra 'saber' goza de estreito parentesco com a gramática das palavras 'poder', 'ser capaz'. Mas também com a gramática da palavra 'compreender'. ('Dominar' uma técnica)" (WITTGENSTEIN, 2009, p. 86).

Quando afirmamos que dois e três são cinco, mostramos que dominamos uma das regras da gramática da Aritmética.

A gramática não é responsável por nenhuma realidade. São as regras gramaticais que determinam o significado (que o constituem) e, portanto, elas próprias não são responsáveis por qualquer significado e, nessa medida, são arbitrárias. (WITTGENSTEIN, 2003, p. 139).

Os sistemas de numeração não dependem do conceito de número. 0 sistema de numeração romana é composto por sete letras maiúsculas do alfabeto latino: I, V, X, L, C, D e M. Os algarismos de menor ou igual valor à direita são acrescidos ao algarismo de maior valor, e algarismos de menor valor à esquerda são subtraídos do algarismo de maior valor. Algarismos indo-arábicos são os dez dígitos 0, 1, 2, 3, 4, 5, 6, 7, 8 e 9, criados com base no sistema numérico decimal. Todos os sistemas têm alguns traços em comum, tais como a representação de numerais, 
mas que pode variar de um povo para outro.

O que são os números? O que os numerais significam; uma investigação do que significam é uma investigação da gramática dos numerais. O que estamos procurando não é uma definição do conceito de número, mas uma exposição da gramática da palavra "número" e dos numerais. (WITTGENSTEIN, 2003, p. 253).

A Aritmética nos aponta para as regras das operações com os números inteiros, tal que 0 algoritmo da divisão, por exemplo, pode ser aplicado quando o aprendiz compreende o sentido da operação. A relação entre saber o sentido da operação e sua utilização está expressa na gramática da palavra dividir, bem como no aprendizado de fazer estimativas. Posso dividir 14 por 2 e encontrar 70 ?

Os signos da linguagem matemática estão conectados de tal forma que obedecem às suas regras gramaticais. A soma do dos quadrados de a e $b-a^{2}+b^{2}-e$ quadrado da soma de $a$ e $b-(a+b)^{2}$ - são expressões regidas por regras diferentes e por este motivo têm significados diferentes. Cunha (2017) afirma que "as regras e convenções do Matematiquês definem o 'alfabeto', a formação de 'palavras', bem como a sintaxe e a semântica de sentenças matemáticas. Há regras gerais que podem, no entanto, sofrer uma pequena alteração em função do dialeto considerado" (p. 47). A gramática do Matematiquês — tratado como língua estrangeira - é composta por regras e convenções. Os dialetos são algebrês, logiquês, geometriquês, trigonometriquês, entre outros (CUNHA, 2017).

A linguagem matemática, ao adquirir sonoridade por intermédio da linguagem natural, passa pela mesma relação de polissemia desta última, mesmo que "para falar bem 0 Matematiquês, é necessário inicialmente falar bem a língua nativa [natural], a fim de que 0 problema a ser estudado seja apresentado, na língua nativa, com clareza e precisão, sem ambiguidades (CUNHA, 2017, p. 51). As regras matemáticas para serem compreendidas devem ser ensinadas e treinadas. Não se aprende o sentido de uma regra aplicando-a uma única vez. É preciso a prática de utilização da regra para que seu sentido seja construído.

\section{Aplicação de regras matemáticas}

Para Wittgenstein, nós não interpretamos regras, nós as seguimos. Quando interpretamos fazemos hipóteses que podem se revelar falsas ou verdadeiras. Seguir uma regra é um livre jogo da imaginação (BENOIST, 2011). 
Pode dizer-se que faz matemática aquele que aplica uma regra de decodificação? E, no entanto, suas transformações podem interpretar-se assim. Pois poderia dizer, certamente, que calcula que há de resultar da decodificação do signo... de acordo com tal e tal chave. E a proposição: os signos..., decodificados de acordo com esta regra, dão por resultado..., é uma proposição matemática (WITTGENSTEIN, 1987, p. 218).

Uma regra de decodificação é similar à uma regra de tradução; "encontrar o produto lógico oculto é uma tarefa matemática" (WITTGENSTEIN, 2014, p. 129), tal como encontrar o produto lógico da operação $753 \div 3$. O professor não pode antecipar todos os casos de aplicação de uma regra, como também não pode antecipar os casos em que não se aplicam tal regra. 0 professor explica uma regra, mas o aluno pode aplicá-la de modo errado devido à incompreensão do sentido das palavras pronunciadas.

Fazemos agora com que o aluno continue uma série (p. ex., "+ 2") acima do no 1000, ele escreve: 1000, 1004, 1008, 1012. Dizemos-lhe: "Veja o que você está fazendo!" Ele não nos compreende. Nós Ihe dizemos: "Você deve adicionar dois; veja como começou a série!". Ele responde: "Sim! Não está correto? Eu pensei que devia fazer assim". Ou suponha que ele dissesse, apontando para a série: "Eu continuei de fato da mesma maneira!" Não adiantaria nada dizer "Mas você não vê ...?"e repetir-lhe as explicações e os exemplos anteriores. Em tal caso, poderíamos dizer talvez: Este homem, por natureza, compreende aquela ordem baseado na nossa explicação, tal como nós compreendemos a ordem: "Some sempre 2 até 1000, 4 até 2000, 6 até 3000 etc. (WITTGENSTEIN, 2009, § 185).

O desenvolvimento da série pelo aluno mostra que ele entendeu que o professor tenha dito "acrescente 4 a mil, depois 8 , depois 12 etc.". Aprendemos o significado de uma palavra no seu uso da mesma forma que aprendemos aplicar a linguagem no cálculo de uma multiplicação. O uso efetivo de uma palavra depende do contexto em que ela está sendo aplicada. A letra 'b' é a sucessora de 'a' considerando nosso alfabeto, já no conjunto das vogais seria 'e'. No meio político dizemos que o presidente Trump é o sucessor de Obama. 0 sucessor de ' $x$ ', no universo da Matemática, quando $x$ pertence ao conjunto dos números naturais, é ' $x+1$ ' e assim podemos fazer muitos outros usos da palavra sucessor, porém não temos como regular seu uso. A codificação de um de seus usos característicos tais como na linguagem matemática é mostrada na escola, mas não impede que o aluno confunda com outros usos que não pertencem à Matemática,

pois não existem todas estas manifestações — de dor, de desejo, de intenção, de recordação etc. - antes de que houvesse uma linguagem?" Qual é a manifestação da dor? "Que é uma mesa?" "Bom, isso, por exemplo." E isto é, por suposto, uma explicação, pois o que ensina é a técnica para usar a palavra "mesa". E agora a pergunta é: que explicação Ihe corresponde [a técnica] no caso de uma 'manifestação' da vida mental? (WITTGENSTEIN, 2006, § 165). 
Quando estamos interessados em compreender o que os alunos pensam precisamos escutar o que eles dizem ou ver o que eles escrevem enquanto fazem exercícios matemáticos. Eles aprendem a descrever o que é visto utilizando palavras e assim vão se apropriando de diferentes jogos de linguagem nas aulas de Matemática.

\begin{abstract}
Fazer cálculos de cabeça talvez seja o único caso em que na vida cotidiana se faz um uso regular da imaginação. É por esta razão que resulta particularmente interessante. Mas sei que ocorreu algo em mim!" O quê? Não foi feito contas na cabeça? Assim, apesar de tudo fazer contas na cabeça é algo específico. Em primeiro lugar, considera isto: Como se usa, em geral, a descrição: Está fazendo contas de cabeça", "Estou fazendo contas de cabeça"? A dificuldade com que se topa aqui é a vagueza nos critérios para a existência do processo mental. Poderia ser eliminada essa vagueza? (WITTGENSTEIN, 2006, §649).
\end{abstract}

Fazer cálculos de cabeça é similar a fazer cálculos no papel. As regras utilizadas para os dois tipos de cálculos são as mesmas. As técnicas desenvolvidas servem para ambos casos. A diferença dos cálculos produzidos no ofício de construção de imóveis e os cálculos realizados em atividades escolares está na objetivação de sua escrita. Feirantes, por exemplo, fazem alguns cálculos mentais com bastante desenvoltura, mas têm dificuldades de fazer cálculos escritos porque não dominam as técnicas de desenvolvimento da escrita matemática (SILVEIRA e SILVA, 2016).

A aplicação de regras matemáticas está intrinsicamente relacionada à construção de conceitos. Wittgenstein (2009) afirma que obedecemos a uma regra sem refletir, obedecemos a regra cegamente. Mas para efeitos de ensino e de aprendizagem da Matemática, consideramos a interpretação de uma regra como um conceito construído pelo aprendiz. Para ilustrar como esta temática é considerada no campo educacional, apontamos para três pesquisas que mostram como a filosofia da linguagem de Wittgenstein pode contribuir com a Educação Matemática.

Meira (2012), ao desenvolver sua pesquisa envolvendo a aplicação da regra de três simples e composta por estudantes da educação básica, mostra que estes estudantes aplicam regras mecanicamente sem Ihes atribuir sentido devido ao fato de o professor da turma pesquisada utilizar uma estratégia própria, que não obteve sucesso no ensino dessas regras.

Em sua pesquisa, que trata da aplicação do algoritmo da divisão, Silva (2011) afirma que não podemos atribuir à explicação dada pelo professor, por exemplo, a multiplicação de um número por zero, o motivo das confusões dos alunos. Quando um professor ensina uma regra, ela não pode abranger todos os casos de sua aplicação; o algoritmo da divisão, por exemplo, não 
pode prever novos contextos de uso. Dessa forma, o autor adverte que uma vez explicada a regra não há garantia de que não haverá mal-entendidos e que não existe uma explicação de uma regra que esteja imune a equívocos.

Oliveira (2012), em sua pesquisa, buscou compreender algumas formas de ver objetos matemáticos de alunos do Ensino Médio e como tais formas poderiam influenciar na aprendizagem de Geometria. A pesquisa revelou diferentes formas de ver, tais como o ver sinóptico e o ver como (WITTGENSTEIN, 2009). 0 autor destaca que essas formas de ver definem a interpretação da Geometria de acordo com o contexto em que ocorre a aprendizagem. Numa escola técnica, os alunos são preparados com algumas regras geométricas para uma maior desenvoltura em relação a alunos de outras escolas, justamente porque eles aprendem a ver sólidos geométricos em diferentes perspectivas, devido os ensinamentos recebidos na disciplina de desenho técnico. Ver para Wittgenstein é uma forma de interpretar; ver a apótema de uma pirâmide quadrangular regular como a hipotenusa do triângulo retângulo de catetos formados pela altura da pirâmide e apótema da base da pirâmide. Essa forma de ver exige o conhecimento de técnicas para ver o sólido e desenhá-lo no espaço da forma que consiga destacar aspectos relacionados com conceitos matemáticos que envolvem a figura.

Essas três pesquisas apontam para os problemas encontrados pelos alunos ao seguir regras matemáticas tendo como referencial teórico a filosofia da linguagem de Wittgenstein. A importância de um bom ensino da gramática da Matemática, tanto na aplicação de regra de três simples ou composta, na aplicação do algoritmo da divisão e na aplicação de regras geométricas, nos faz perceber que a interpretação dessas regras pelos estudantes sofre perturbações de ordem gramatical. A pesquisa de Meira aponta para o problema de o professor não escolher um bom caminho para explicitar a regra que pretende ensinar; a pesquisa de Silva aponta para o problema de o professor não dar conta de explicar todas as aplicações do algoritmo da divisão, ou seja, de explicar uma regra em todos seus diferentes contextos de aplicação, já a pesquisa de Oliveira aponta para a diferença do estudante que tem seu olhar treinado a perceber as nuances de um sólido geométrico em detrimento da soma das áreas de suas faces e seu volume, por exemplo.

\section{Considerações}

Nesse texto buscamos compreender o funcionamento da gramática da Matemática de acordo com os pressupostos teóricos da filosofia da linguagem de Wittgenstein e posteriormente 
podemos constatar estes pressupostos utilizados em pesquisas educacionais que buscavam analisar os problemas de aplicação de regra matemática em situações de ensino e de aprendizagem.

A gramática da Matemática reúne um conjunto de regras que determinam como os conceitos matemáticos se entrelaçam no automovimento da Matemática que independem da empiria. A conexão entre os conceitos forma uma rede conceitual que está assentada a objetividade da Matemática. Vimos que tanto Caveing como Wittgenstein creditam a necessidade da Matemática de criar novas regras que dependem umas das outras.

As pesquisas educacionais pautadas no uso da linguagem natural e matemática pretendem apontar os problemas que os estudantes encontram em lidar com textos matemáticos. Partimos do pressuposto que não temos acesso ao pensamento do aluno e, assim, nos resta analisar suas verbalizações e suas escritas. É recomendável que o professor forneça a oportunidade ao aluno de se expressar oralmente, pois na linguagem oral podemos nos expressar mais facilmente, bem como retomar a palavra quando percebemos que nossa exposição não foi adequada. O professor também pode compreender as dúvidas dos alunos, as suas confusões na interpretação das palavras utilizadas no momento de uma explicação do professor ou de um texto escrito no livro didático.

Sabemos que muitos conflitos na comunicação das pessoas são originários de interpretações das palavras. Num debate, nos perguntamos dos motivos pelos quais nosso adversário pronunciou determinadas palavras. 0 debate continua na tentativa de esclarecermos 0 uso de algumas palavras, isso é uma prova que nosso discurso pode ser mal interpretado. Da mesma forma na sala de aula, não estamos isentos dos efeitos da polissemia de nossa linguagem natural e nada melhor que um bom diálogo para que sejam dissolvidos tais conflitos.

Como a gramática da Matemática possui diferentes regras que estão associadas à forma de sua linguagem, é nela que podemos buscar a compreensão de conceitos matemáticos.

\section{Referências}

BENOIST, Jocelin. Les limites de l'interprétation. In: CHAUVIRÉ, Christiane (Org.). Wittgenstein et les questions du sens. Paris: L'art du comprendre, 2011, p. 147-162.

CAVEING, Maurice Louis Frederich Emile. Le problème des objets dans la pensée Mathématique. Paris: Librairie Philosophique J. Vrin, 2004. 
CHAUVIRÉ, Christiane. Le moment anthropologique de Wittgenstein. Paris: Kimé, 2008.

CUNHA, Sueli. Considerações sobre a aprendizagem contínua do matematiquês: a linguagem matemática. In: MAIA, Madeline Gurgel Barreto; BRIÃO, Gabriela Félix. (Org.). Alfabetização matemática: perspectivas atuais. Curitiba: CRV, 2017, p. 45-59.

MEIRA, Janeisi de Lima. Labirintos da compreensão de regras em Matemática: um estudo a partir da regra de três. 2012. 99f. Dissertação (Mestrado em Educação em Ciências e Matemáticas) Instituto de Educação Matemática e Científica. Universidade Federal do Pará. Belém.

MLIKA, Hamdi. La contribuition de Maurice Caveing dans la mise au jour de l'universalisme omniculturel des Mathématiques. In: COLLOQUE HUMANISMES, MATHÉMATIQUES, POSITIVISMES, Peyresq, 2007. Actes du Colloque. Peyresq, 2007.

OLIVEIRA, Marcelo Sousa; SILVEIRA, Marisa Rosâni Abreu. Falar e mostrar para provar: uma contribuição teórica sobre a utilização dos gestos ostensivos wittgensteinianos como auxiliares como auxiliares na prova Matemática. Alexandria, Florianópolis, v. 9, n. 2, jul./dez. 2016.

OLIVEIRA, Rodolfo Ronaldo Nobre. "Ver como": uma vivência do olhar para a aprendizagem de Geometria. 2012. 109f. Dissertação (Mestrado em Educação em Ciências e Matemáticas) Instituto de Educação Matemática e Científica. Universidade Federal do Pará. Belém.

SILVA, Paulo Vilhena da. 0 aprendizado de regras matemáticas: uma pesquisa de inspiração wittgensteiniano com crianças da $4^{a}$ série no estudo da divisão. 2011. 102f. Dissertação (Mestrado em Educação em Ciências e Matemáticas) - Instituto de Educação Matemática e Científica. Universidade Federal do Pará. Belém

SILVEIRA, Marisa Rosâni Abreu; SILVA, Paulo Vilhena da. O cálculo e a escrita matemática na perspectiva da filosofia da linguagem: domínio de técnicas. Educação Matemática Pesquisa, São Paulo, v. 18, n. 1, p. 469-483, jan./abr. 2016.

SIMÕES, Eduardo. Wittgenstein e o problema da verdade. Belo Horizonte: Argvmentvm, 2008.

WITTGENSTEIN, Ludwig. Escrito a máquina. Traducción de Jesús Padilla Gálvez. Madri: Trotta, 2014.

WITTGENSTEIN, Ludwig. Fichas (Zettel). Tradução de Ana Berhan da da Costa. Lisboa: Edições 70, 1989.

WITTGENSTEIN, Ludwig. Gramática filosófica. Tradução de Luis Carlos Borges. 2. ed. São Paulo: Edições Loyola, 2003.

WITTGENSTEIN, Ludwig. Investigações Filosóficas. Tradução de Marcos Montagnoli. 6. ed. Petrópolis: Vozes, 2009.

WITTGENSTEIN, Ludwig. Le Cahier bleu et le Cahier brun. Gallimard: Mesnil-sur-l'Estrée, 2010.

WITTGENSTEIN, Ludwig. Observaciones sobre la Filosofía de la Psicología. Traducción de Luis Felipe Segura. México: Instituto de Investigaciones Filosóficas, 2006. 
WITTGENSTEIN, Ludwig. Observaciones sobre los fundamentos de la Matemática. Traducción de Isidoro Reguera. Madrid: Alianza Editorial, 1987.

WITTGENSTEIN, Ludwig. Remarques sur les fondements des mathématiques. Mayenne: Éditions Gallimard, 1983.

WITTGENSTEIN, Ludwig. Vocabulaire à l'usage des écoles primaires. Tradução de Jean-Pierre Cometti. Revue Litteraire Bimestrielle. Marseille, p. 233-234, 1986. 